\title{
THE EFFECT OF CHLORPROMAZINE ON HAEMOSTASIS *
}

\author{
Allen B. Dobkin, M.D., Lyman M. Fisher, PH.D., and \\ GoRDON M. Wyant, F.f.A.R.C.S.
}

RECENT STUDIES INDICATE that the lethal effect of experimental, traumatic and chronic haemorrhagic shock is decreased or preverted by pre-treatment with chlorpromazine $(1,2)$. In animals this treatment also attenuates the deleterious influence of bacterial invasion, and when bacterial contamination does occur, congestion and haemorrhage in the bowel does not develop (3). In a clinical study of patients undergoing surgical treatment for pulmonary tuberculosis, it was found also that pre-treatment with chlorpromazine possibly prevented or minimized the decompensatory uptake of blood following severe or prolonged haemorrhage and improved the postoperative course of these patients (4).

This protective action of chlorpromazine has been partially explained on physiological, pharmacological and psychological grounds. Physiologically, the major known effect of the drug is to decrease peripheral vascular resistance. This causes hypotension and reduces the head of pressure in the peripheral circulation $(5,6)$. Zweifach and associates believe that the protection afforded by chlorpromazine is due to the block of neurogenic peripheral vascular control and a hyper-reactive response by the arterioles and venules to vaso-active materials in the circulation during stress (7). This hyper-reactivity sustains regional blood flow in the presence of a decreased circulating blood volume more effectively than sympathetic over-compensation in response to stress as seen in the unprotected or unblocked peripheral circulation. This effect is noted both in the visceral and in the peripheral (skin) circulation. The hyper-reactivity of arterioles and venules is considered a favourable sign, indicating that the deleterious pooling of blood in the splanchnic area, as seen in irreversible shock, has been eliminated and that a sustained circulation of the skin and peripheral vascular bed is present in spite of depletion of the blood volume.

Pharmacologically, there is a potent anti-adrenalin effect, a protective action on the heart against epinephrine-induced arrhythmias of chloroform, cyclopropane and trichlorethylene; a slight anti-histaminic effect, an anti-acetylcholine (parasympatholytic) effect; and a potent anti-5-hydroxytryptamine effect. There is also a moderate local anaesthetic effect and a "pharmacological leucotomy" which extends from the level of the cortex to the brain stem and to the cervical ganglia $(8,9,10,11,12,13)$.

Psychologically, chlorpromazine suppresses primary epinephrine-precipitable subcortical warning or tension anxiety. It exerts only an indirect influence on the secondary cortical manifestations, consisting of the traumatic state of the ego, in inverse proportion to the degree to which important ego functions have been

\footnotetext{
-From the Department of Anaesthesia and Physiology, University of Saskatchewan College of Medicine and University Hospital, Saskatoon.

This work was supported by the National Research Council of Canada.
} 
disrupted in the direction of paralysis or inhibition by the anxiety. These are the reasons why chlorpromazine is most effective in manic states or severe anxiety states. These conditions are most directly power-driven in the direction of excitation by epinephrine-precipitable tension anxiety, and in which important ego functions are weakened least. The majority of these neuro-psychological effects are mediated through the reticular activating system $(14,15)$.

Other sources of chlorpromazine's protective action have been sought. It is possible that it has some effect on haemostasis and on the distribution of circulating blood volume. These two were, therefore, studied in patients who were under the stress of preparation for an elective surgical operation. The following is the report on the effect of chlorpromazine on haemostasis.

In haemostasis three mechanisms must be studied by the clinician: the maintenance of the integrity of vessel walls, the clumping of blood platelets and agglutination of red cells, and the coagulation of the blood. As noted by Jaques (16), if two of these are impaired it is unlikely that haemorrhage can be prevented. Trauma results in contraction of the damaged vessels and decrease in vessel permeability which is partly dependent on liberation of a vasoconstrictor substance, 5-hydroxytryptamine, from platelets. The platelets along with the red cells serve as a mechanical plug at the site of injury, contribute thromboplastin to the third mechanism of defence, the clotting process, and influence clot retraction to produce a firm blood clot. The release of 5-hydroxytryptamine and epinephrine by the platelets causes agglutination of the plug.

The coagulation of the blood consists of a series of rather complicated biochemical reactions. The basic mechanisms of coagulation can be considered as taking place in three phases in a step-wise fashion as suggested by Biggs: activation of thromboplastin; transformation of prothrombin to thrombin; and, finally, the formation of fibrin. Defects in clotting may occur in any one of these phases owing to deficiencies of essential clotting elements. Recent investigations have done much to elucidate factors previously unknown which play an important role in the coagulation process. Many of these recently discovered factors can by considered as accelerators of the over-all transformation to evolve fibrin. On the other hand, one must not forget the possibility of the release and appearance of inhibitors of this process.

The activation of the thromboplastin is brought about by platelets (platelet factors) plus thromboplastinogen (normally in the plasma) to form thromboplastin. Secondly, the conversion of prothrombin to thrombin involves thromboplastin plus prothrombin to form thrombin. Several factors speed up these reactions, including ionized calcium, accelerator globulin (labile factor) and convertin globulin (stable factor). Deficiency of accelerator or convertin factors may delay clotting, while inhibitors in the blood may minimize intravascular clotting. Finally, the formation of fibrin must occur from the thrombin and fibrinogen.

During and following operation, poor haemostasis may develop as the result of two primary defects in the clotting mechanism-deficiency of major clotting elements, and deficiency of essential accelerator factors. A minor defect involves excessive production of inhibitors. 
In order to follow properly the sequence of the clotting mechanism, a systematic investigation of all facets of coagulation should be undertaken. Such an analysis was attempted in this study to evaluate the effect of the drug chlorpromazine on haemostasis, utilizing the coagulogram recommended by Bell (17). This is similar to the system of the tests advocated by Seegers and a number of other workers $(18,19,20,21)$. In reviewing the literature, Siegers (18) reported conflicting data as to the effects of anaesthetics and respiratory gases on clotting power of the blood. Epinephrine produced hyper-coagulability, while acetylcholine apparently caused fibrinolysis. Parsloe and associates (20) recently studied the effects of opiate premedication, and of muscle relaxant drugs in combination with thiobarbiturates, for induction of anaesthesia and various systems of maintenance on the clotting of blood, and found a variable response that would indicate no obvious derangement of the clotting mechanism.

It is essential in these studies to realize the limitations of the methods used. Changes in the haemostasis of the patient caused by stress or drugs may be in the coagulant or, as mentioned above, in the anti-coagulant phase and may include changes in the rate of physiological formation or destruction of the major elements of blood clotting. Drugs may also act by entering into direct combination with a coagulant or anti-coagulant or influence the release of either from storage depots. The techniques presently employed for the stucy of these effects may not reveal minor alterations.

The following procedures were employed to determine the effect of chlorpromazine on blood clotting. Studies were carried out on patients who were scheduled for elective operation. Male patients between the ages of. 18 and 76 were selected who were well nourished but not obese, and who had relatively normal heart, lungs, liver, blood counts and circulating blood volume. Tests were carried out the day before operation, 45 minutes after the intravenous injection of chlorpromazine, one hour postoperatively (if blood loss and fluid replacement was minor) and two days postoperatively. None of these patients had received ACTH nor were undergoing surgical procedures involving organs which might cause fibrinogenopenia or a bleeding tendency (21). One patient underwent tonsillectomy under local anaesthesia (H.R.). The remainder had thiopental and nitrous oxide and the relaxant $\mathrm{d}$-tubo curare for their anaesthetic.

\section{TECHNiques}

Hematocrit (PCV) was determined by filling a Sandford-Magath tube to the $1 \mathrm{ml}$. mark with 1.1 per cent sodium oxalate solution and adding $5 \mathrm{ml}$. of venous blood into the oxalate, then the tube was stoppered and inverted two to three times. The stopper was then removed and the tube centrifuged at 2,500 r.p.m. for 30 minutes. The volume of the packed red cells excluding the "buffy coat" was read and muliplied by 20 to determine the hematocit. Normal value is $47 \pm 7$ per cent for males.

Haemoglobin was determined with cyanmethaemoglobin standard solutions as provided by the National Research Council on a Coleman Junior Spectrophoto- 
meter. Limits of confidence in this laboratory are \pm 0.37 grams in the 10 to 18 gram range.

Bleeding time was determined by two methods. One (Duke) was carried out in all cases and is reported; the other was discontinued as this procedure is not routinely used. In the Duke method the lobe of the ear was cleansed with alcohol and a $2 \mathrm{~mm}$. cut (length and depth) was made with a No. 11 Parker knife. Every 5 to 10 seconds the droplet of blood was blotted with filter paper until bleeding stopped. The second method (which was discontinued) is the Ivy technique as described by Stefanini. The sphygmomanometer cuff applied to the arm was inflated to $40 \mathrm{~mm}$. $\mathrm{Hg}$ and after cleansing the skin of the forearm with alcohol, a $2 \mathrm{~mm}$. cut (length and depth) was made with a No. 11 Parker knife. Drops of blood were collected on filter paper every 15 to 30 seconds until there was complete cessation of bleeding. Normally bleeding stops within 3 minutes.

Clotting time was measured by a modification of the Lee and White method: $10 \mathrm{ml}$. of venous blood was drawn for each coagulation cletermination into a siliconed syringe. Immediately, the first $2 \mathrm{ml}$. of blood were placed in an oxalated tube as were the last $5 \mathrm{ml}$. The middle $3 \mathrm{ml}$. were placed, $1 \mathrm{ml}$. in each of three, $10 \times 75 \mathrm{~mm}$. glass culture tubes and a stop watch started. The first tube was tilted every 30 seconds for the first 3 minutes and then every 15 seconds thereafter until a clot formed. The second tube was then tilted every 15 seconds until a clot appeared and finally the third tube was likewise tilted. The formation of a clot in the third tube was taken as the end point and recorded as the clotting time. Normal values range from 7 to 15 minutes. The oxalated blood was used in the remainder of the study.

Prothrombin determinations. The one-stage method modified from Quick (22), was used. The measurement of the plasma clotting time (prothrombin time) after the addition of thromboplastin and calcium indicates the minimal interval that elapses before a microscopic fibrin clot results from the conversion of prothrombin to thrombin. The value indicates the velocity and amount of thrombin formation from the interaction of prothrombin with calcium, thromboplastin and certain "accessory" substances; the velocity of the thrombin-fibrinogen interaction and deposition of the insoluble fibrin gel; and the competitive effect of antithrombin inactivating the thrombin. The prime purpose of the one-stage prothrombin method is to measure the over-all velocity of thrombin elaboration. However, no indication is given of the mechanism of thromboplastin formation since the latter is added artificially to the system. The one-stage procedure was modified upon occasion for the detection of deficiency of proconvertin (factor VII) (23). For this a small amount of human serum was added to the experimental plasma in the one-stage prothrombin. Fibrinogen leve!s were measured according to the technique described by Quick (22). Normal is 1.5 to $3.5 \mathrm{mg} . / \mathrm{ml}$. plasma.

For the specific determination of prothrombin, the two-stage method described by Ware and Seegers was used (24). This depends on the entire conversion of prothrombin to thrombin, which is then measured by the clotting of a fibrinogen solition previously standardized against known amounts of thrombin. For this 
TABLE I

\begin{tabular}{|c|c|c|c|c|c|c|c|c|c|c|c|}
\hline$\stackrel{\overrightarrow{\tilde{E}}}{\vec{E}}$ & $\stackrel{\varrho}{\Xi}$ & $\stackrel{0}{\not \infty}$ & 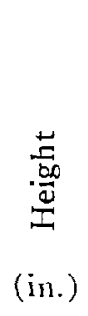 & $\begin{array}{l}\frac{5}{\frac{5}{60}} \\
\stackrel{\frac{60}{2}}{3} \\
\text { (lb.) }\end{array}$ & $\begin{array}{c}\dot{c} \\
\dot{n} \\
\infty \\
\text { (sq.m.) }\end{array}$ & 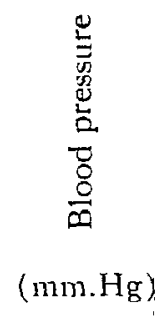 & 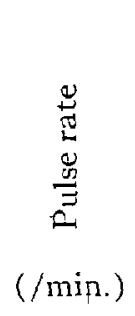 & $\begin{array}{c}\stackrel{\dot{c} 0}{\stackrel{.}{I}} \\
\text { (gm.) }\end{array}$ & $\begin{array}{c}\dot{u} \\
\ddot{\sim} \\
\left(\times 10^{6}\right)\end{array}$ & $\begin{array}{l}3 \\
(\%)\end{array}$ & 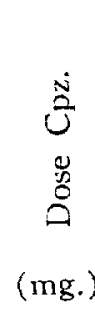 \\
\hline CT & $\begin{array}{l}a \\
b \\
c \\
d\end{array}$ & 18 & 67 & 122 & 1.63 & $\begin{array}{l}120 / 70 \\
124 / 74 \\
120 / 80 \\
120 / 70\end{array}$ & $\begin{array}{r}84 \\
112 \\
100 \\
80\end{array}$ & $\begin{array}{l}16.5 \\
15.2 \\
16.2 \\
16.2\end{array}$ & $\begin{array}{l}5.29 \\
4.80 \\
4.95 \\
5.23\end{array}$ & $\begin{array}{l}50 \\
47\end{array}$ & 25 \\
\hline HR & $\begin{array}{l}a \\
b \\
c \\
d\end{array}$ & 20 & 73 & 169 & 1.97 & $\begin{array}{l}150 / 70 \\
110 / 60 \\
170 / 90\end{array}$ & $\begin{array}{r}80 \\
120 \\
120\end{array}$ & $\begin{array}{l}15.7 \\
16.6 \\
16.0\end{array}$ & $\begin{array}{l}5.47 \\
5.30 \\
5.01\end{array}$ & $\begin{array}{l}46 \\
49\end{array}$ & 25 \\
\hline$J R$ & $\begin{array}{l}d \\
a \\
b \\
c \\
d\end{array}$ & 28 & 68 & 161 & 1.85 & $\begin{array}{l}124 / 60 \\
124 / 80 \\
112 / 78 \\
132 / 78 \\
130 / 80\end{array}$ & $\begin{array}{l}64 \\
80 \\
80 \\
64 \\
60\end{array}$ & $\begin{array}{l}15.7 \\
16.2 \\
15.5 \\
15.0 \\
16.5\end{array}$ & $\begin{array}{l}5.03 \\
4.76 \\
4.98 \\
4.47 \\
4.87\end{array}$ & $\begin{array}{l}52 \\
48 \\
45 \\
48 \\
48\end{array}$ & 24 \\
\hline$W C$ & $\begin{array}{l}w \\
a \\
b \\
c \\
d\end{array}$ & 33 & 70 & 161 & 1.87 & $\begin{array}{l}120 / 80 \\
108 / 80 \\
120 / 90 \\
126 / 88\end{array}$ & $\begin{array}{l}92 \\
96 \\
88 \\
72\end{array}$ & $\begin{array}{l}15.5 \\
15.7 \\
16.0 \\
16.2\end{array}$ & $\begin{array}{l}5.00 \\
4.61 \\
4.72 \\
5.00\end{array}$ & $\begin{array}{l}45 \\
45 \\
44 \\
45\end{array}$ & 40 \\
\hline IA & $\begin{array}{l}a \\
b \\
c \\
d\end{array}$ & 37 & 69 & 210 & 2.08 & $\begin{array}{l}130 / 70 \\
110 / 82 \\
114 / 56 \\
124 / 80\end{array}$ & $\begin{array}{l}80 \\
92 \\
72 \\
76\end{array}$ & $\begin{array}{l}14.6 \\
14.6\end{array}$ & $\begin{array}{l}4.61 \\
4.68\end{array}$ & $\begin{array}{l}46 \\
+4\end{array}$ & 40 \\
\hline WS & $\begin{array}{l}a \\
a \\
b \\
c \\
d\end{array}$ & 43 & 63 & 157 & 1.73 & $\begin{array}{l}124 / 80 \\
140 / 85 \\
130 / 86 \\
140 / 80 \\
136 / 80\end{array}$ & $\begin{array}{l}10 \\
82 \\
74 \\
88 \\
76\end{array}$ & $\begin{array}{l}14.0 \\
17.4 \\
17.2 \\
15.1 \\
15.7\end{array}$ & $\begin{array}{l}4.80 \\
5.53 \\
5.50 \\
4.48 \\
4.86\end{array}$ & $\begin{array}{l}+1 \\
51 \\
50 \\
49 \\
44\end{array}$ & 25 \\
\hline WG & $\begin{array}{l}a \\
b \\
c \\
d\end{array}$ & 50 & 71 & 174 & 1.97 & $\begin{array}{l}140 / 80 \\
130 / 80 \\
110 / 70 \\
130 / 80\end{array}$ & $\begin{array}{r}80 \\
102 \\
78 \\
80\end{array}$ & $\begin{array}{l}16.7 \\
16.2 \\
16.0 \\
15.0\end{array}$ & $\begin{array}{l}5.21 \\
5.09 \\
5.08 \\
5.03\end{array}$ & $\begin{array}{l}48 \\
49\end{array}$ & 30 \\
\hline WH & $\begin{array}{l}a \\
b \\
b \\
c \\
d\end{array}$ & 53 & 68 & 130 & 1.68 & $\begin{array}{r}110 / 70 \\
90 / 46 \\
112 / 72 \\
110 / 66\end{array}$ & $\begin{array}{l}70 \\
76 \\
78 \\
70\end{array}$ & $\begin{array}{l}14.4 \\
14.6 \\
14.7 \\
14.4\end{array}$ & $\begin{array}{l}4.83 \\
4.65 \\
4.66 \\
4.73\end{array}$ & $\begin{array}{l}42 \\
43 \\
42 \\
37\end{array}$ & 25 \\
\hline JM & $\begin{array}{l}a \\
b \\
c \\
d\end{array}$ & 57 & 69 & 160 & 1.86 & $\begin{array}{l}110 / 60 \\
110 / 70 \\
110 / 60 \\
128 / 74\end{array}$ & $\begin{array}{l}80 \\
60 \\
80 \\
76\end{array}$ & $\begin{array}{l}16.7 \\
15.7 \\
14.8 \\
14.2\end{array}$ & $\begin{array}{l}5.20 \\
5.14 \\
4.99 \\
4.75\end{array}$ & $\begin{array}{l}47 \\
48 \\
50 \\
48\end{array}$ & 25 \\
\hline$C D$ & $\begin{array}{l}a \\
b \\
c \\
d\end{array}$ & 66 & 73 & 143 & 1.85 & $\begin{array}{r}116 / 72 \\
90 / 62 \\
110 / 70\end{array}$ & $\begin{array}{r}84 \\
88 \\
100\end{array}$ & $\begin{array}{l}13.3 \\
11.9\end{array}$ & $\begin{array}{l}4.57 \\
4.18\end{array}$ & $\begin{array}{l}41 \\
50 \\
42\end{array}$ & 25 \\
\hline FK & $\begin{array}{l}d \\
a \\
b \\
c \\
d\end{array}$ & 67 & 67 & 145 & 1.75 & $\begin{array}{l}120 / 72 \\
120 / 74 \\
110 / 69 \\
114 / 70 \\
120 / 60\end{array}$ & $\begin{array}{l}84 \\
68 \\
96 \\
76 \\
70\end{array}$ & $\begin{array}{l}14.0 \\
14.4 \\
14.0 \\
14.0 \\
13.5\end{array}$ & $\begin{array}{l}4.40 \\
4.59 \\
4.36 \\
4.71 \\
4.65\end{array}$ & $\begin{array}{l}44 \\
40 \\
45 \\
43 \\
40\end{array}$ & 25 \\
\hline $\mathrm{DC}$ & $\begin{array}{l}a \\
b \\
c \\
d\end{array}$ & 68 & 69 & $1+2$ & 1.77 & $\begin{array}{l}140 / 70 \\
130 / 80 \\
154 / 90 \\
140 / 60\end{array}$ & $\begin{array}{l}80 \\
74 \\
64 \\
76\end{array}$ & $\begin{array}{l}11.5 \\
11.9 \\
10.0 \\
12.5\end{array}$ & $\begin{array}{l}3.53 \\
3.96 \\
3.51 \\
4.42\end{array}$ & $\begin{array}{l}42 \\
40 \\
42 \\
42\end{array}$ & 25 \\
\hline GT & $\begin{array}{l}a \\
a \\
b \\
c \\
d\end{array}$ & 76 & 72 & 195 & 2.08 & $\begin{array}{l}170 / 00 \\
130 / 80 \\
100 / 58 \\
110 / 60 \\
130 / 80\end{array}$ & $\begin{array}{l}74 \\
86 \\
72 \\
80\end{array}$ & $\begin{array}{l}11.5 \\
11.0 \\
11.1 \\
11.3\end{array}$ & $\begin{array}{l}3.84 \\
3.31 \\
3.72 \\
3.70\end{array}$ & $\begin{array}{l}42 \\
40 \\
40 \\
32 \\
35\end{array}$ & 25 \\
\hline
\end{tabular}


TABLE II

\begin{tabular}{|c|c|c|c|c|c|c|c|c|c|c|c|c|}
\hline 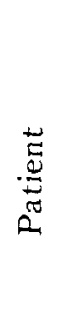 & 邑 & $\begin{array}{c}\dot{d} \\
\dot{U} \\
\dot{0} \\
\stackrel{0}{0} \\
\text { (mg.) }\end{array}$ & 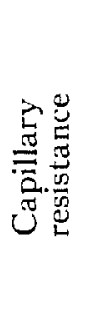 & 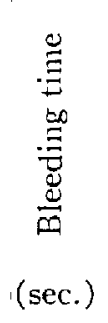 & 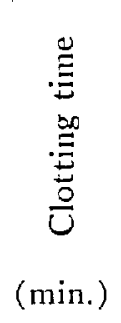 & 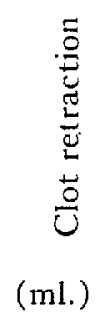 & 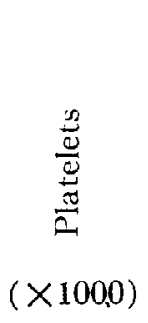 & 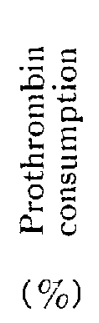 & 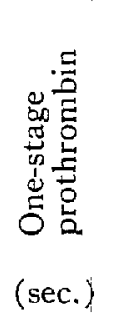 & 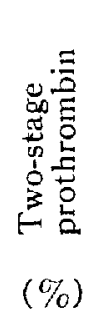 & 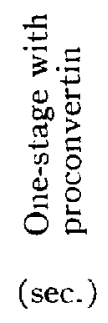 & 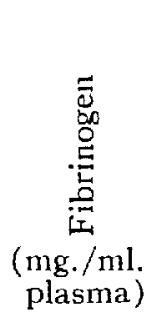 \\
\hline \multirow[t]{4}{*}{$\mathrm{CT}$} & $a$ & & 0 & 30 & 9 & .4 & 258 & 10 & 15.0 & 100 & & 3.0 \\
\hline & $b$ & 25 & 0 & 30 & 11.5 & .38 & 286 & 10 & 14.6 & 110 & & 3.6 \\
\hline & $c$ & & 0 & 70 & 13 & .38 & 210 & 10 & 17.2 & 110 & & 6.0 \\
\hline & $d$ & & 0 & 40 & 11.5 & & 205 & 10 & 15.0 & 100 & 14.6 & \\
\hline \multirow[t]{4}{*}{$\mathrm{HR}$} & $a$ & & 0 & 90 & 11 & .43 & 282 & 10 & 13.2 & 60 & & 2.3 \\
\hline & $b$ & 25 & 0 & 40 & 12 & .43 & 266 & 10 & 16.6 & 60 & & 1.0 \\
\hline & $c$ & & 0 & 55 & 10 & & 280 & 10 & 14.0 & 100 & & 1.0 \\
\hline & $d$ & & 0 & 75 & 12 & .36 & 275 & 10 & 19.7 & 100 & 14.8 & 2.0 \\
\hline \multirow[t]{4}{*}{ JR } & $a$ & & 0 & 35 & 7 & & 200 & 10 & 13.6 & 60 & & 7.0 \\
\hline & $b$ & 25 & 0 & 30 & 8 & & 260 & 10 & 14.8 & 55 & & 2.9 \\
\hline & $c$ & & 0 & 30 & 6 & .35 & 204 & 10 & 13.6 & 70 & & 2.6 \\
\hline & $d$ & & 0 & 40 & 17 & & 270 & 15 & 13.8 & 100 & & 2.9 \\
\hline \multirow[t]{4}{*}{ WC } & $a$ & & 0 & 30 & 12 & .30 & 181 & 25 & 15.6 & 110 & & 2.0 \\
\hline & $b$ & 40 & 0 & 30 & 15 & .28 & 291 & 20 & 15.4 & 90 & & 1.0 \\
\hline & $c$ & & 0 & 90 & 13 & .30 & 181 & 10 & 16.0 & 120 & & \\
\hline & $d$ & & 0 & 35 & 17 & .10 & 235 & 17 & 17.0 & 80 & 15.0 & \\
\hline \multirow[t]{4}{*}{ IA } & $a$ & & 0 & 75 & & .43 & 372 & 10 & 12.7 & 67 & & 1.3 \\
\hline & $b$ & 40 & 0 & 60 & 11 & .45 & 263 & 10 & 22.5 & 40 & & 1.0 \\
\hline & $c$ & & 0 & & 7 & .37 & 275 & 10 & 12.4 & 40 & & 1.0 \\
\hline & $d$ & & 0 & 45 & 8.5 & .45 & 202 & 10 & 11.0 & 70 & & 1.7 \\
\hline \multirow[t]{4}{*}{ WS } & $a$ & & 0 & 45 & & & 167 & 10 & 13.2 & 72 & & 2.0 \\
\hline & $b$ & 25 & 0 & 35 & & .35 & 256 & 10 & 16.6 & 67 & & 1.7 \\
\hline & $c$ & & 0 & 30 & 7 & .42 & 232 & 10 & 14.0 & 72 & & 1.4 \\
\hline & $d$ & & 0 & 30 & 11 & .35 & 242 & 10 & 19.7 & 70 & & 2.3 \\
\hline \multirow[t]{4}{*}{ WG } & $a$ & & 0 & 95 & 10 & & & 10 & 17.2 & 70 & & 1.0 \\
\hline & $b$ & 30 & 0 & 55 & 9 & .40 & 227 & 10 & 19.0 & & & 0.7 \\
\hline & $c$ & & 0 & 55 & 8 & & 186 & 10 & 16.5 & 100 & & 0.5 \\
\hline & $d$ & & 0 & 35 & 12 & .36 & 241 & 10 & 19.6 & 110 & 13.8 & \\
\hline \multirow[t]{4}{*}{ WH } & $a$ & & 0 & 120 & 8 & .40 & 262 & 10 & 15.2 & 70 & & 3.9 \\
\hline & 6 & 25 & 0 & 45 & 12 & .38 & 265 & 10 & 17.0 & 100 & & 2.4 \\
\hline & $c$ & & 0 & 60 & 13 & & & 30 & 16.4 & 60 & & 2.4 \\
\hline & $d$ & & 0 & 30 & 10 & .30 & 295 & 10 & 16.0 & 60 & & \\
\hline \multirow[t]{4}{*}{$\mathrm{JM}$} & $a$ & & 0 & 40 & 13 & .35 & 240 & 10 & 15.0 & & & 4.4 \\
\hline & $b$ & 25 & 0 & 30 & 16 & .38 & & 10 & 13.0 & 80 & & 1.7 \\
\hline & $c$ & & 0 & 30 & 12 & & 170 & 10 & 12.0 & & & 1.4 \\
\hline & $d$ & & 0 & 30 & 11 & .35 & 168 & 15 & 15.4 & 75 & & 5.2 \\
\hline \multirow[t]{4}{*}{$\mathrm{CD}$} & $a$ & & 0 & 30 & 19 & .20 & & 40 & 19.0 & & & \\
\hline & $b$ & 25 & 0 & 45 & 17 & .37 & 200 & 15 & 12.4 & 100 & & \\
\hline & $c$ & & 0 & & 24 & .45 & 150 & 25 & 14.0 & & & \\
\hline & $d$ & & 0 & 30 & 13 & .32 & 220 & 10 & 17.2 & & & \\
\hline \multirow[t]{4}{*}{ FK } & $a$ & & 0 & 60 & 12 & .50 & 275 & 10 & 16.0 & 67 & & \\
\hline & $b$ & 25 & 0 & 55 & 7 & .32 & 226 & 10 & 18.8 & 67 & & \\
\hline & $c$ & & 0 & 60 & 7 & .50 & & 20 & 17.0 & 67 & & \\
\hline & $d$ & & 0 & 30 & 11 & & 268 & 20 & 15.2 & 100 & & 2.9 \\
\hline \multirow[t]{4}{*}{$\mathrm{DC}$} & $a$ & & 0 & 45 & 7 & & & 10 & 13.8 & & & 3.0 \\
\hline & $b$ & 25 & 0 & 45 & 17 & .38 & 246 & 10 & 14.2 & 50 & & 3.6 \\
\hline & $c$ & & 0 & 45 & 18 & .25 & 242 & 10 & 13.8 & 100 & & 6.0 \\
\hline & $d$ & & 0 & 30 & 15 & .25 & 260 & 10 & 13.4 & 90 & & \\
\hline \multirow[t]{4}{*}{ GT } & $a$ & & 0 & 60 & 18 & .42 & 320 & 15 & 15.8 & & & 3.9 \\
\hline & $b$ & 25 & 0 & 35 & 10 & & 176 & 10 & 16.6 & 50 & & 6.5 \\
\hline & $c$ & & 0 & 45 & 6 & & & 15 & & & & 1.4 \\
\hline & $d$ & & 0 & 60 & 12 & & 235 & 40 & 13.0 & 45 & & \\
\hline
\end{tabular}


method to be valid, all factors required for complete thrombin elaboration must be present, and thrombin inactivation by antithrombins is avoided by dilution in the system (normally 80 to 110 per cent).

Prothrombin consumption test. When normal blood is placed in a glass test tube, most of the prothrombin will disappear within 60 minutes after the blood is shed. This is believed to be due to its conversion to thrombin. In a severe deficiency of serum prothrombin conversion accelerator (SPCA) and in bleeding states of haemophiloid nature the residual serum prothrombin is far greater after coagulation is allowed to run its course than under normal circumstances. Accordingly, serum containing less that 25 per cent of the parent plasma prothrombin may be considered strong evidence against any of these coagulation defects.

Clot retraction time was measured by the method of Andreassen as quoted by Tocantins (25) and modlfied as follows. One ml. of blood was allowed to clot in a siliconed (G.E. drifilm SC 87) vessel in the centre of which was a glass rod. The blood adheres to the rod but not to the siliconed vessel. The latter was inverted at the end of 2 hours and the expressed serum collected and measured in a graduate tube (normally 0.25 to $0.35 \mathrm{ml}$.).

Platelets were counted directly using the method of Kristenson (26) (normal $200,000$ to 300,000$)$.

\section{REsUlts}

The cases studied are summarized in Tables I and II. An analysis of the coagulation system revealed that changes had occurred in the clotting mechanism of the individual from the time the control was taken until after chlorpromazine was administered. In most instances the changes took the form of a moderately increased clotting time and a prolonged one-stage prothrombin time. However, four of the eleven cases with complete data showed a shortening of the clotting time, so that the prolongation was not necessarily due to chlorpromazine. This indicates the variableness of response or perhaps it indicates that the stress reaction was not adequately suppressed.

The increase in the one-stage prothrombin time was found to be due to a deficiency of proconvertin (factor VII, SPCA). Alterations in the two-stage prothrombin values verified the change in the one-stage prothrombin time. There also appeared to be a slight fall in the level of fibrinogen. No change was noted in the clot retraction value, platelet count or in the prothrombin consumption.

Variations were also found in the postoperative studies, but showed no conssstency among the patients studied and are attributable more probably to the anaesthesia and the operation. The stress of the latter may have an effect on the clotting system since it has been found that various forms of stress can elevate the one-stage prothrombin time (27).

The decrease in peripheral vascular resistance by chlorpromazine is produced by the fall in blood pressure in most patients. This was not accompanied by any change in the capillary resistance as measured by the tourniquet test. The control 


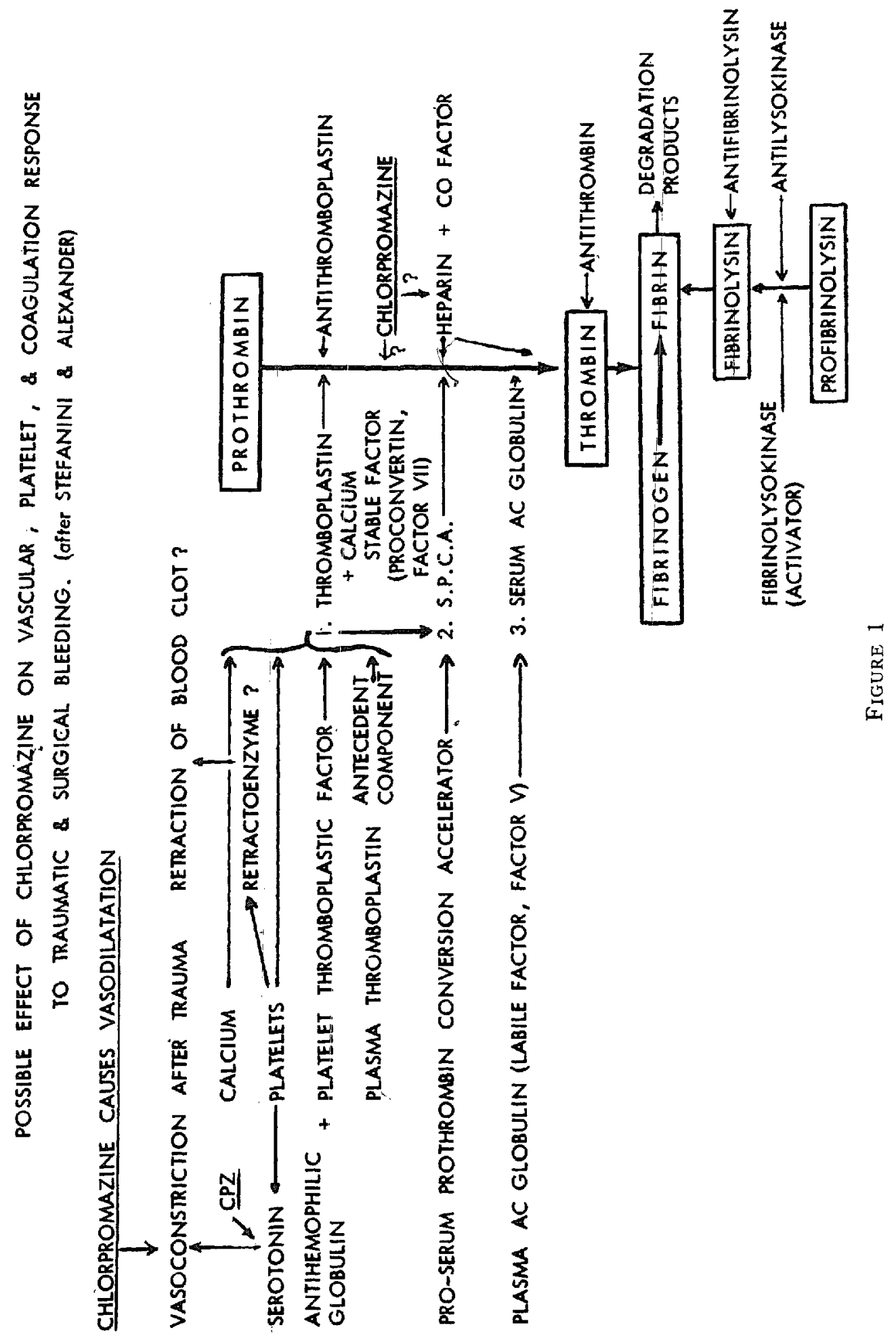


bleeding time in most patients was quite short and could be attributed to the psychological stress of impending operation. Although chlorpromazine produces an anti-adrenalin and anti-serotonin effect, bleeding time tended to be even shorter than in the control. This may indicate added stress in the immediate preoperative period which is not completely allayed by premedication. This effect persisted into the postoperative period (Fig. 1).

\section{Discussion}

Although it is generally recognized that the normal vascular function, particularly of the small vessels, plays an important part in haemostasis, there is far less understanding of this function than of the clotting mechanism itself. This is unfortunate because in approximately 50 per cent of all haemorrhagic disorders no abnormality in coagulation is demonstrable despite present knowledge. Even with the newer concepts one must keep an open mind as new and radical changes in this knowledge are revealed (19).

Before the effect of drugs on haemostasis can be assessed, a working hypothesis of the haemostatic mechanism, based on established fàcts, must describe the sequence of events in traumatic or surgical bleeding for the clinical investigator. Stefanini (21) has summarized this as follows Surgical bleeding occurs at the level of the metarteriole. When the vessel is cut, a fleeting, localized vasoconstriction takes place Shortly afterward, platelets and red cells agglutinate at the site of injury. This physical phenomenon is followed by a more prolonged and more systemic constriction of all metarteriolar vessels, which is attributed to release of 5-hydroxy-tryptamine from disintegrating platelets. Coagulation of blood also seems to start at this time. Once fibrin has been formed, the clot begins to retract. The fibrolytic mechanism in this process is not clearly understood, and the formation of fibrin is the most complicated step. Basically, this mechanism involves the reaction of a platelet factor with anti-haemophilic globulin to form thromboplastin with assistance of several plasma factors. The thromboplastin then reacts with calcium and a stable factor (cothromboplastin, factor VII, convertin) to form an intermediate complex that reacts with the labile factor (factor V, accelerin) to form a prothrombin-convertin agent (plasma thromboplastin, prothrombinase) which converts prothrombin to thrombin in the presence of calcium. As fibrinogen is acted on by thrombin in the presence of an optimal concentration of calcium and a poorly defined factor found in plasma and serum, fibrin is finally formed The factors supplied by platelets seem to accelerate the formation of thrombin and fibrin.

Chlorpromazine has been postulated to affect haemostasis in two major ways: by increasing the efficiency of coagulation; or by preventing fibrinolysis. On the other hand, Courvoisier (8) has shown that the coagulation time of blood in animals is prolonged by the administration of chlorpromazine. This effect may be related to the anti-adrenalin or the ant1-serotonin effect of chlorpromazine.

Kovács and associates (28) have recently shown in animals that chlorpromazine c'ears lipaemia presumably by moblizing endogenous heparin. Their hypothesis is supported by the fact that the clearing effect appears rapidly, bringing about 
a shift in the lipo-protein pattern similar to that produced by heparin, and that the effect is inhibited by protamine. If a rise in heparin occurs in this way, the clotting mechanism may be disturbed at several points since heparin prevents the activation of prothrombin to thrombin by an anti-prothrombin action, and a powerful anti-thrombin effect inhibits the action of thrombin in converting fibrinogen to fibrin. Heparin also reduces or prevents the lysis and agglutination of platelets and, therefore, reduces production of plasma thromboplastinogen.

Perlick (29) reported that the phenothiazine derivatives used to produce prolonged sleep therapy may increase the heparin content of the blood. Kovács also points out that since the phenothiazine derivatives have come into wide use in therapy, several observations have suggested that thrombo-embolic complications frequently occur following prolonged use of these drugs. On the basis of experiments it might be assumed that owing to the increased release of heparin during prolonged phenothiazine treatment the heparin stores throughout the body become diminished and the interruption of continuous administration may be followed by a sudden decrease of the heparin blood level. The possibility that such a mechanism is in operation was suggested to explain an increased coagulability of the blood after the administration of chlorpromazine. However, the evidence regarding human heparin is still very scanty and it would be premature to relate to humans any data obtained from animals.

In this study, the single intravenous injection of a therapeutic dose of chlorpromazine showed no consistent change in platelet count or the clotting time either after the drug or after anaesthetic and the operation. The only significant change was a prolongation of the one-stage prothrombin time (in nine of thirteen patients). This probably indicates an inadequate suppression of the stress response by chlorpromazine in the doses administered

\section{SUMMARY}

A study of the effect of chlorpromazine on the haemostatic mechanism was carred out on thirteen adult male patents in relatively good general health and who were under the stress of preparation for an operation. A reduction in blood pressure indicated a significant decrease in peripheral vascular control, and a decrease in the prothrombin time occurred in most of the patients. These changes did not persist into the postoperative period. Under these clinical conditions and by this technique of study, it was found that chlorpromazine may decrease the coagulability during operation and may increase coagulability postoperatively. The cause of these changes was not revealed

\section{ACKNOWLEDGMENT}

The authors sincerely appreciate the advice and assistance by Professor L B. Jaques.

\section{RÉSUMÉ}

Nous avons fart une étude de l'effet de la chlorpormazine sur le mécanisme homeostatıque de treize hommes en bonne santé relative mais subissant le stress 
de la préparation à une opération. Nous avons observé une diminution notable du controle vasculaire páriphérique manifesté par l'abaissement de la pression artérielle et une diminution du temps de prothrombine chez la plupart des malades. Après l'opération, ces modifications n'existaient plus. Dans ces conditions cliniques et avec cette façon d'étudier, nous avons observé que le chlorpromazine peut diminuer la coagubilité pendant l'opération et l'augmenter dans les suites opératoires On n'a découvert l'étiologie de ces modifications.

\section{REFERENCES}

1 Kelan, M \& \& ZweIfach, B. W The Influence of Partal and Complete Evisceration on the Action of Drugs Protecting against Lethal Hemorrhage Surg, Gynec \& Obst 99. 707 (1954)

2 Spurr, G. B, Farrand, E A, \& Horvath, S M. Effect of Chlorpromazme on Survival from Hemorrhagic Shock Am. J Physiol. 185. 499 (1956).

3 Hershey, S. G, Guccione, I \& Zweifach, B W Beneficial Action of Pretreatment with Chlorpromazme on Survival following Graded Hemorrhage in the Rat Surg, Gynec \& Obst. 101: 431 (1955)

4 Dobkin, A B, Wemling, B, Gross, G., \& Mendelsohn, H. Chlorpromazine in Anaesthesia for Surgical Treatment of Pulmonary Tuberculosis Anaesthesia 10: 328 (1955)

5 Dobkin, A. B, Lamoureux, L., \& Gilbert, R G B Conservative Therapy of Peripheral Vascular Disease with Use of Largactil. Treat Serv Bull. 9. 324 (1954).

6 Dobkin, A. B., Lamouneux, L, \& Gilbert, R. G B Physiological Effects of Chlorpromazine Anaesthesia 9157 (1954)

7 Hershey, S G, Zweifach, B W, \& Antopol, N Factors Associated with Protection against Experımental Shock Anesthesiology 17: 265 (1956)

8 Courvorsier, S, Fournel, J., Ducrot, R, Kolsky, M , \& Koetschet, P Propriétés pharmacodynamiques du chlorhydrate de chloro-3-(dimethylamino-3-propyl)-10-Phenothiazıne ( $4560 \mathrm{RP}$ ) Etude experımentale d'un nouveau corps utulisé dans l'anesthésie potentialisée et dans l'hıbernation artıficielle Arch internat de pharmacodyn $92 \quad 305$ (1953).

9. Melvilie, K. I. Observations on Adrenergic-Blocking and Antifibrilatory Actions of Chlorpromazine Fed Proc 13.386 (1954)

10. Dobkin, A B, Grbert, R G B, \& Melville, K I. Chlorpromazine Review and Investigation as a Premedicant in Anesthesia Anesthesiology 17 135 (1956)

11 Bourgeors-Garvaroin, M, Nowill, W K., Margolis, G, \& Stephen, C R. Chlorpromazıne A Laboratory and Clinical Investigation Anesthesılogy 16829 (1955).

12 LeCOMTE, J 5-Hydroxytryptamine et membrane nictitante du chat Arch internat pharmacodyn. 100457 (1955).

13 Bendit, E P, \& Rowley, D A Antagonusm of 5-Hydroxytryptamine by Chlorpromazine Science 12324 (1956)

14 Alexander, L Therapeutic Process in Electroshock and the Newer Drug Therapies J A M A 162966 (1956)

15 Dobkin, A B, Kilduff, C J, \& WYant, G M Indications for Chlorpromazine in Clinical Anaesthesia Anesth \& Analg 36(2) 38 (1957)

16. Jaques, L. B. Blood Clotting and Haemostasis from the Standpoint of the Anaesthetist Canad Anaesth Soc. J 4. 104 (1957)

17 Betl, W N The Chinical Use of a Coagulogram M Clin North Amenca 371843 (1953)

18 SEegrers, $W$ H The Influence of Certain Drugs on Blood Coagulation and Related Phenomena Pharmac Rev 3 278 (1951)

19 Alexander, B. Coagulation Hemorrhage and Thrombosis New Engl. J Med 252. 432, 484,526 (1955). 
20 Parslot, G., Deutsci, H., \& Orth, O. S. The Effects of Muscle Relaxant Drugs on Blood Clotting. Anesth \& Analg. 33. 358 (1954).

21 Stefanini, M Problems in Bleeding Disorders. Postgrad. Med 19. 420 (1956).

22 Quick, A J. The Physiology and Pathology of Hemostasıs, p. 142. Philadephta Lea and Febiger (1951).

23 Brggs, R, \& Macfarlane, R. G. Human Blood Coagulation and Its" Disorders, p 352. Springfield, Ill. C. C. Thomas (1951)

24. Ware, A. G., \& Seegers, W. H. Two-Stage Procedure for the Quantitative Determination of Prothrombin Concentration. Am. J Clin. Path. 19. 471 (1949).

25 Andreassen, M. Quoted in L. M. Tocantins, The Coagulation of Blood, Methods of Study, pp. 30-32 New York: Grune \& Stratton (1955)

26 Kristenson, A Modified by $H$ Lempert, A Modified Technique for the Enumeration of Blood Platelets. Lancet $I$, 151 (1935).

27 Jaques, L B, \& Chubaty, W. An Effect of Stress on the Prothrombin Time. Rev. d'Hematol. 9. 523 (1954).

28 Kovács, B M., Kovács, G S , \& Pentri, G. Lipaemia Clearing Effect of Chlorpromazine. Experientia 12.376 (1956)

29 Perlick, E. Quoted by B M. Kovács, et al. Langenbecks Ach. Klin. Chir. 279: 799 (1954) 